\title{
Comparative Study of Objectively Structured Versus Traditional Viva-Voce in Microbiology amongst Second-Year MBBS Students
}

\author{
Poorva A. Sule ${ }^{1}$, Milind R. Ubale ${ }^{1}$, Sundaram Kartikeyan ${ }^{2}$, Deepali D. \\ Belurkar $^{1}$, Vrushali V. Kulkarni ${ }^{2}$ \\ ${ }^{1}$ Microbiology Department, Rajiv Gandhi Medical College, Kalwa, Thane, Maharashtra, India \\ ${ }^{2}$ Community Medicine Department, Rajiv Gandhi Medical College, Kalwa, Thane, Maharashtra, India
}

\begin{abstract}
This comparative educational interventional study was conducted at Rajiv Gandhi Medical College, Kalwa, Thane, Maharashtra, India to assess the difference in the marks obtained by students in traditional vivavoce (TVV) and objectively structured viva-voce (OSVV) examination formats and to evaluate the perception of students regarding OSVV. After obtaining institutional approvals and written informed consent, participating second-year MBBS students $(n=62)$ were oriented about OSVV format. Assessment as per TVV format followed that using the OSVV format (both out of 20 marks) on the same day. Feedback comprising nine closed-ended questions (Likert scale) and one open-ended question was obtained from the participants. The marks obtained were statistically analysed and feedback was evaluated. While there was no significant difference ( $p=0.2357$; $Z=0.72$ ), significant correlation (linear relationship; $p<0.01, r=0.44$ ) was observed between marks obtained in the two viva-voce formats. Majority of students were satisfied with OSVV in relation to syllabus coverage, duration for answering, relevancy of questions, avoidance of subjectivity/bias and fifty percent felt that difficulty level was well maintained. There was significant correlation between the marks obtained in the two formats of viva voce, though the participants preferred OSVV format.
\end{abstract}

Keywords: Microbiology, Objectively structured viva-voce, Viva-voce, Gender bias

\section{Introduction}

A viva-voce, an essential component of examination in medical courses, can assess all five cognitive domains - knowledge, comprehension, application, analysis, and synthesis. [1] Various medical universities in India use this format in summative and formative examinations. [2] The traditional viva voce (TVV) examination has many limitations, such as validity, objectivity, comprehensiveness, inter-evaluator variability, repeatability, and possible gender bias. [3-5] In order to address these issues, an objectively structured viva voce (OSVV) format has been proposed. The OSVV format provides every candidate with equal opportunity of fair and standardized assessment while testing his/her knowledge, clinical skills and attitude. [6]

\section{Objectives}

This study was conducted to assess the difference in the marks obtained by students in traditional and structured method of viva examination and to evaluate the perception of students of structured viva examination.

\section{Materials And Methods}

3.1: Study area: The study was conducted at Rajiv Gandhi Medical College, Kalwa, Thane, located about 30 $\mathrm{km}$ from Mumbai city, Maharashtra state, India.

3.2. Procedure: After obtaining approval from Institutional Ethics Committee, Microbiology faculty formulated recall and analytical type questions for viva-voce examination and the evaluation pattern and allotment of marks was determined. Written informed consent was obtained from Second-year (fourth semester) MBBS students $(\mathrm{n}=62)$, who were explained about OSVV format and the distribution of topics. Different set of teachers conducted TVV and OSVV and allotted marks out of 20 in each format. After TVV, the students appeared for OSVV on the same day. The allotted time for OSVV was seven minutes per student. The overall time taken for the TVV was recorded. Feedback comprising nine closed-ended questions (five-point Likert scale) and one open-ended question was obtained from the students.

3.3 Statistical analysis: The marks obtained were tabulated on Microsoft Excel. The mean, standard deviation, relative deviate " $\mathrm{Z}$ " and Karl Pearson's correlation coefficient " $\mathrm{r}$ " were calculated. Feedback forms were evaluated and responses were expressed as percentages. Confidence interval was expressed as [Mean$1.96 *($ Standard error $)]-[$ Mean+1.96*(Standard error)]. Statistical significance was considered at $\mathrm{p}<0.05$. 


\section{Results And Discussion}

4.1. Scores obtained by students: A total of 62 fourth semester MBBS students ( 38 females and 24 males) participated in this study. While there was no significant difference $(\mathrm{p}=0.472 ; \mathrm{Z}=0.72)$, significant correlation (linear relationship; $\mathrm{p}<0.01, \mathrm{r}=0.44$ ) was observed between marks obtained in the two viva-voce formats. (Table 1) The average marks obtained in TVV were $53.83 \pm 14.01$ while that obtained in OSVV were $51.89 \pm 16.12$. However, this difference was not statistically significant $(\mathrm{p}=0.24)$. Fair agreement between OSVV and TVV scores has been also reported by a study [7] from Sawangi (Wardha, Maharashtra). In contrast to results obtained in the current study, a study [8] from Bhuj, Gujarat has found poor co-relation between marks obtained in the two viva-voce formats. A similar study [2] from Patan, Gujarat has reported that greater variation in the average marks allotted by two different examiners in TVV as compared to those allotted in OSVV and that students obtained significantly less marks in the OSVV format.

Table 1: Mean and standard deviation of scores obtained by students $(n=62)$

\begin{tabular}{|l|c|c|c|c|}
\hline Parameter & $\begin{array}{c}\text { Traditional } \\
\text { viva voce }\end{array}$ & $\begin{array}{c}\text { Objectively } \\
\text { structured viva voce }\end{array}$ & $\begin{array}{c}\text { Z value } \\
\#\end{array}$ & p value \\
\hline Mean & 10.77 & 10.38 & \multirow{2}{*}{0.72} & \multirow{2}{*}{0.472} \\
\hline Standard deviation & 2.80 & 3.22 & & \\
\hline Confidence interval & $10.07-11.47$ & $9.58-11.18$ & \\
\hline
\end{tabular}

\# Standard error of difference between two means

4.2. Time taken for viva-voce: The time taken for the TVV ranged between $3 \mathrm{~min}$ and $10 \mathrm{~min}$, whereas, for OSVV, fixed time of $7 \mathrm{~min}$ was allotted and 10 questions (covering all topics, with increasing difficulty levels) were asked within that time-frame. In the current study, a 7 min time period was found to be optimum and satisfactory, although other researchers have stated varying time limits ranging from $8 \mathrm{~min}-25 \mathrm{~min}$. [7, 9]

4.3. Gender differences in scores: Though the maximum TVV score and third quartile was similar for both genders, the median TVV score, first quartile and minimum TVV score was much lower for males. The maximum, third quartile, median, first quartile OSVV scores for females was much higher than that for males. However, the minimum OSVV score obtained by males was marginally higher than that for females. (Fig. 1) Gender differences in scores were not statistically significant (Table 2).

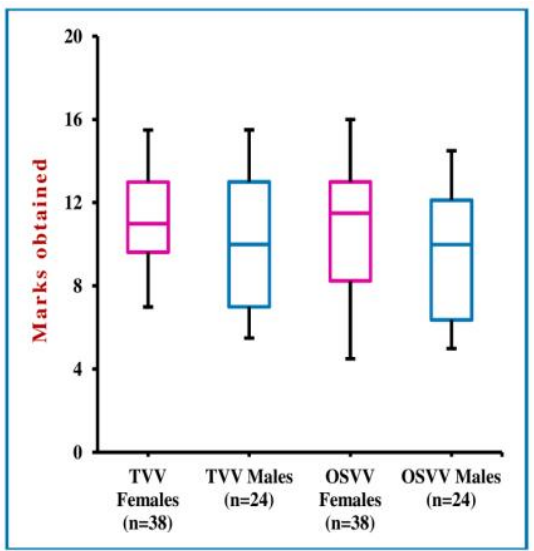

Fig. 1: Box-and-whisker plot depicting gender-wise distribution of scores TVV = Traditional viva-voce; OSVV = Objectively structured viva-voce

Some studies [10-12] have explicitly quoted students' perception about possible gender bias during examinations. A British study [13] found that both gender and ethnicity influenced performance in undergraduate medical examinations. Another British study [14] reported that females perform well in coursework while males do so in unseen examinations. However, an eight-year American study found statistically significant gender difference in scores, particularly in course assessment and short answer questions but did not specifically mention about gender bias. [15] In the present study, gender differences in scores were not statistically significant and there was no evidence for gender bias, as reported by some other studies.

Table 2: Gender differences in mean and standard deviation of scores

\begin{tabular}{|l|c|c|c|c|}
\hline \multirow{2}{*}{ Viva voce format } & \multicolumn{2}{|c|}{ Mean \pm Standard deviation } & Z value & \multirow{2}{*}{$\mathrm{p}$ value } \\
\cline { 2 - 3 } & Females $(\mathrm{n}=38)$ & Males $(\mathrm{n}=24)$ & $\#$ & \\
\hline Traditional viva voce & $11.16 \pm 2.44$ & $10.15 \pm 3.26$ & 1.304 & 0.192 \\
\hline Objective structured viva voce & $10.96 \pm 3.15$ & $9.46 \pm 3.18$ & 1.816 & 0.069 \\
\hline
\end{tabular}

\# Standard error of difference between two means 
4.4. Feedback: Majority of students were satisfied with OSVV in relation to "justice" to level of preparation, syllabus coverage, duration for answering, relevancy of questions, avoidance of subjectivity/bias and fifty percent felt that difficulty level was well maintained. (Fig. 2) The open-ended students' feedback on OSVV is outlined in Table 3.

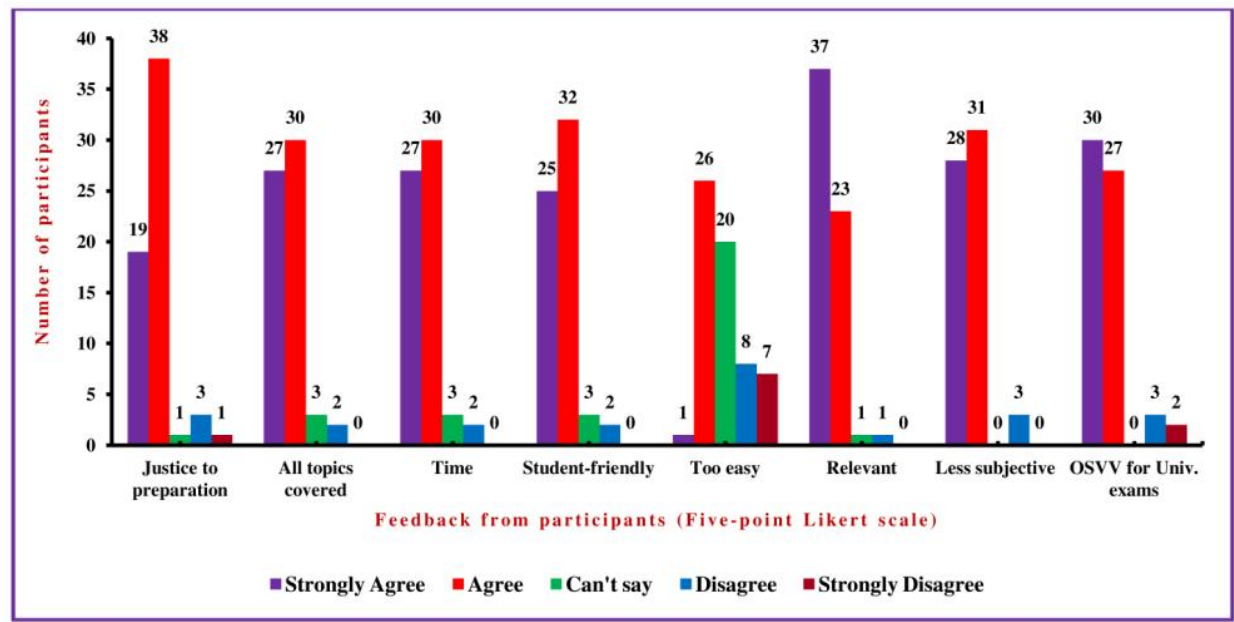

Fig. 2: Students' perception: Preference for objectively structured viva-voce over traditional viva-voce

Table 3: Open-ended feedback from students regarding OSVY

\begin{tabular}{|l|c|}
\hline \multicolumn{1}{|c|}{ Points mentioned in open-ended feedback } & Percentage of students $(\mathrm{n}=62)$ \\
\hline Not just favourite questions of examiner & 64.0 \\
\hline Reduced "luck factor" in exam & 35.5 \\
\hline To-the-point (precise) questions & 27.4 \\
\hline Reduced personal bias & 21.0 \\
\hline Helpful in preparation for final exam & 01.6 \\
\hline I realised what I know from the entire syllabus & \\
\hline
\end{tabular}

By analysing the OSVV mark sheets, the weaker topics were identified, which enabled revision of topics and remedial actions. In the feedback obtained from students on OSVV, majority of students were satisfied about coverage of syllabus, justice given to preparation along with the level of difficulty maintained in viva. (Fig. 2) Students' perception about OSVV was similar to that reported by other studies. $[10,16]$ The OSVV also helped in giving detailed feedback to the students as the score-sheet of question-answers for each student was maintained by examiner. In addition, teachers could identify the topics that were not understood by the students (viz. blood culture, biochemical reactions, Clostridium, anaerobiosis). Hence, analyzed OSVV scores can be used to facilitate modification of teaching in future.

4.5. Limitations: The inter-rater variability was not ascertained and the study was limited to one semester examination, with limited topics.

\section{Conclusion}

There was significant correlation between marks obtained by the students in the two formats of vivavoce. OSVV was preferred by the fourth semester students and was found to enable provision of feedback to students regarding their level of preparation and helped the faculty in identifying weaker areas, and scope for improvement.

\section{Acknowledgements}

This project was done as a part of Advance Course in Medical Education Technology - 2015 (GSMCMCI Nodal Centre, Mumbai, India). The authors thank all the teaching staff of Microbiology Department, Rajiv Gandhi Medical College for their co-operation.

\section{References}

[1] B. S. Bloom, M. D. Englehart, E. J. Furst, and D. R. Krathwol, in B. S. Bloom (Ed.), Taxonomy of educational objectives: The classification of educational goals. Handbook I: The Cognitive Domain (New York: David McKay Co Inc, 1956).

[2] K. Khilnani, J. Charan, R. Thaddanee, R. R. Pathak, S. Makwana, and G. Khilnani, Structured oral examination in pharmacology for undergraduate medical students: Factors influencing its implementation, Indian J Pharmacol, 47(5), 2015, 546-550.

[3] N. Rahman, S. Ferdousi, N. Hoq, R. Amin, and J. Kabir, Evaluation of objective structured practical examination and traditional practical examination, Mymensingh Med J, 16(1), 2007, 7-11. 
[4] S. Khan, H. Acemoglu, and Z. Akturk, An objective structured biostatistics examination: a pilot study based on computer-assisted evaluation for undergraduates, J Educ Eval Health Prof, 9, 2012, 9.

[5] S. Ferdousi, S. A. Latif, M. M. Ahmed, and A. Nessa, Summative assessment of under graduate medical student's performance in physiology by structured oral examination, Mymensingh Med J, 16(1), 2007, 64-69.

[6] S. Hassan, Oral examination as objective structured authentic viva (OSAV), Nishtar Med J, 3(3 \& 4), 2011, 35-40.

[7] P. V. Puppalwar, A. Rawekar, A. Chalak, A. Dhor, and M. P. Khapre, Introduction of Objectively structured viva-voce in formative assessment of medical and dental undergraduates in biochemistry, J Res Med Edu Ethics, 4(3), 2014, 321-325.

[8] S. K. Gor, D. Budh, and B. M. Athanikar, Comparison of conventional viva examination with objective structured viva in second year pathology students, Int J Med Sci Pub Health, 3(5), 2014, 537-539.

[9] P. K. Rangachari, The targeted oral, Adv Physiol Educ, 28, 2004, 213-214

[10] K. R. Shenwai, and K. B. Patil, Introduction of Structured Oral Examination as A Novel Assessment tool to First Year Medical Students in Physiology, J Clin Diag Res, 7(11), 2013, 2544-2547.

[11] J. Vankudre, B. D. Almale, M. S. Patil, and A. M. Patil, Structured oral examination as an assessment tool for third year Indian MBBS undergraduates in community medicine, MVPJMS, 3(1), 2016, 33-36.

[12] A. Jaleel, and N. Jaffrey, Perception of medical students on structured viva examination in an integrated undergraduate curriculum at Ziauddin University, J Dow Univ Health Sci, 4(1), 2010, 4-7.

[13] I. Haq, J. Higham, R. Morri, and J. Dacre, Effect of ethnicity and gender on performance in undergraduate medical examinations, Med Educ, 39(11), 2005, 1126-1128.

[14] R. Woodfield, S. Earl-Novell, and L. Solomon, Gender and mode of assessment at university: should we assume female students are better suited to coursework and males to unseen examinations? Assess Eval High Educ, 30(1), 2005, 33-48.

[15] S. Kelly, and R. Dennick, Evidence of gender bias in True-False-Abstain medical examination, BMC Med Educ, 9, $2009,32$.

[16] H. K. Shah, F. S. Vaz, and D. D. Motghare, Structured Oral Examination: From Subjectivity to Objectivity - An experience in Community Medicine, J Educational Res Med Teach, 1(1), 2013, 25-27. 